\title{
Utilization of Prostate Serum Antigen (PSA) Screening Services among the Igala People of North Central Nigeria
}

\begin{abstract}
Prostate cancer according to the world Health Organization is one of the silent killers of the African men. It is associated with avalanche health burden in physical, social and economic dimensions. Consequently, early detection has been identified as the most effective intervention and management of this social malady. This study is a descriptive survey which utilized secondary data to investigate the influence of socio-demographic characteristics on the utilization of the prostate screening services among the Igala people of North Central Nigeria at the Kogi State University Teaching Hospital, Anyigba. The substantive issues of this study were the level of utilization of the PSA services, the influence of socio-demographic characteristics on utilization, motivation for PSA screening as well as the standardized PSA levels of patients. The study utilized secondary data obtained from Kogi State University Teaching Hospital. Study data was collected from the information unit of the hospital following informed consent of the hospital management. The data was analysed using multiple regression analysis through the application of SPSS. 20.0. Findings of the study reveals that the level of utilization of the PSA services among the vulnerable population in the study area is low, motivation for screening is by clinical referrals while PSA levels is generally high. The hypotheses tested revealed that socio-demographic characteristics of the respondents are related to utilization with $(p=0.00)$, patients PSA levels is also socio-demographically determined as $(p=0.12)$ Recommendations from these findings includes: tailored information, health education and the use of reward system by government and non-governmental organizations.
\end{abstract}

\section{Background of the Study}

Prostate Cancer (PC), an adenocarcinoma of the male prostate gland, is progressively becoming a significant health burden among men in the world. However, available literature reveals that PC treatment is possible if there is an early diagnosis, at the time the disease is still localised in the prostrate $[1,2]$. Early detection of the disease is therefore a fundamental component of a successful prostate cancer therapy and one of the common measures adopted is the PSA test. The Prostate Serum Antigen (PSA) test measures the level of PSA in a man's blood. The rationale for screening is to reduce the possibility of developing the disease at the asymptomatic stage. According to the World Health Organisation (2009) [3], this method was adapted from the success recorded in the Breast Examination (BSE) mammography and Pap-smear tests conducted in breast and cervical cancer interventions respectively.

It has been found that $\mathrm{PC}$ is the leading cancer in terms of incidence and mortality in men from Africa and the Caribbean (IARC 2014) [4]. The study also notes that PC is a growing problem in Africa with approximately 28,006 deaths from PC in 2010, and approximately 57,048 deaths projected in 2030 if aggressive interventions are not put in place. Prostate cancer is rarely seen among males below the age

\section{Journal of}

Human Anatomy \& Physiology

\author{
Akwu PB ${ }^{1}$, Shaibu $\mathrm{GO}^{2 *}$ and Omotoso OD ${ }^{1}$ \\ ${ }^{l}$ Department of Human Anatomy, Kogi State University, Anyigba \\ ${ }^{2}$ Department of Sociology, Kogi State University, Anyigba \\ *Address for Correspondence \\ Shaibu GO, Gabriel Ocholi, Department of Sociology, Kogi State \\ University, Anyigba; E-mail: gshaibu81@yahoo.com \\ Submission: 30 June, 2019 \\ Accepted: 16 September, 2019 \\ Published: 18 September, 2019 \\ Copyright: () 2019 Akwu PB, et al. This is an open access article \\ distributed under the Creative Commons Attribution License, which \\ permits unrestricted use, distribution, and reproduction in any medium, \\ provided the original work is properly cited.
}

of 40, the most common cancer among men in Nigeria and Patients usually present with locally advanced disease or metastatic disease at diagnosis with tendency for high Gleason scores. The PC in Nigeria may be as great as that noted in black men in the United States, which may suggest a common enhancing genetic predisposition [5]. Treatment modalities for prostate cancer are proving difficult, and the prognosis of untreated or inadequately managed cases is often usually poor especially in developing countries [6]. This could be attributed to the high cost of medication and surgical interventions required to treat patients with a diagnosed condition [6].

World Health Organization (2009) observes that thirty percent of cancers are curable if detected early while thirty percent of cancers are treatable with prolonged survival if detected early and thirty percent of cancer patients can be provided with symptom management and palliative care. Like many other health problems ravaging developing countries in Nigeria, early detection of prostate cancer has been problematic due to a host of factors which are primarily socioeconomic in nature. Yet, at present, there are no clear strategies towards preventing prostate cancer through life-style modification or preventive intervention and therefore, understanding factors that determine uptake of PC will be highly beneficial as a precautionary measure against the onset of the disease.

Odunayo and Ogundele (2015) have shown that Prostate cancer screening is not a common practice in Nigeria in spite of its place as the most commonly diagnosed cancer in Nigerian men as well as primary intervention [7]. The practical implication of this is that majority of patients usually present in the hospital with the disease at the advanced stage. Although men with advanced stage disease may benefit from palliative treatment, their tumours are generally not curable. Thus, a screening program that could accurately identify asymptomatic men with aggressive localized tumours might be expected to substantially reduce prostate cancer morbidity, including urinary obstruction, painful metastases and mortality [8]. In developed countries, screening for PSA has led to early detection and management of the disease. However, in developing countries particularly in Africa, routine screening has remained low due to 
a host of social, cultural and political factors leading to reduced detection rates, poor management and increased mortality from the disease. Argue that low education has a relationship with prostatic diseases among Blacks in the United States of America [9].

\section{Statement of the Research Problem}

GLOBOCAN Cancer Facts Sheets, 2012 (GCFS, 2012) opines that all men are at risk of developing prostate cancer and about one man in six will be diagnosed with prostate cancer during his lifetime [10]. The burden of prostate cancer in Nigeria is so significant that GCFS (2012) reports indicate that in 2012 there was 307,000 prostate cancer implicates prostate cancer as the fifth leading cause of death from cancer in men ( $6.6 \%$ of the total men deaths) and that the mortality rates are generally high in predominantly black populations. Prostate cancer is a major health problem and the most common cancer in men and the most commonly diagnosed cancer among Nigerian men however; CaP screening is not a common practice in Nigeria Oliver (2008). In Nigeria, Prostate cancer is the most common cancer among men. It is also associated with a high mortality rate $(71 / 100,000)$. Ogundele and Ikwuerowo (2015) attribute the high rate of cancer mortality to advanced prostate cancer presentation by African men [7], emphasizing the need for prevention, earlier detection, and improvements in management of this disease. Odunayo and Ogundele, 2015 have shown that Prostate cancer screening is not a common practice in Nigeria in spite of prostate cancer being the most commonly diagnosed cancer in Nigerian men [7]. Lending credence, many prostate cancer cases therefore present late with symptoms of local invasion or distant metastasis [11]. The primary goal of prostate cancer screening is to reduce avoidable morbidity and mortality through early detection towards achieving prompt management. Though, many studies on the need for prostate cancer screening has been reported in Nigeria, such results and specifically that on demographic characteristics on the study area is non-existent. This present study is anchored on demographic characteristics and utilization of PSA services at the Kogi State University Teaching Hospital, Anyigba.

\section{Research Objectives}

To determine the level of utilization of PSA services among the vulnerable population among the Igala people of Kogi East Senatorial District.

To determine the clients' motivation for the utilization of PSA services.

\section{Research Hypotheses}

1. Socio-demographic characteristics have no influence on utilization of PSA services among patients.

2. Socio-demographic characteristics have no influence on the PSA levels of patients who accessed PSA service at KSUTH.

\section{Materials and Methods}

\section{Research design}

This study is a descriptive and diagnostic research which aims at linking resource socio- demographic characteristics with utilization of Prostate cancer screening services at the Kogi State University
Teaching Hospital, located in Anyigba, Kogi State, Nigeria.

\section{Study area}

The study was conducted in Kogi East Senatorial District of Kogi state, Nigeria.

Kogi State is situated in the savannah region between longitude $05^{\circ} 20^{\prime \prime}-08^{\circ} 00^{\prime \prime}$ East and latitude $05^{\circ} 30^{\prime \prime}-08^{\circ} 50^{\prime \prime}$ North with the State capital at Lokoja, located at the confluence of the two major Rivers in Nigeria, River Niger and River Benuie [12]. The state is bordered to the East by Benue State and to the South by Edo, Enugu and Ondo States and to the North by Niger and Nasarawa States and to the West by Kwara and Ekiti States. The state is made up of twenty-one Local Government Areas (LGAs). The Eastern Flank of the State has 9 local Government Areas dominated by the Igala people who are said to be the 9th populous ethnic group in Nigeria. The place is precisely located between longitude $06^{\circ} 30^{\prime \prime}-07^{\circ} 00^{\prime \prime}$ East and latitude $06^{\circ} 30^{\prime \prime}$ $08^{\circ} 00^{\prime \prime}$ North. There are two main seasons, dry and wet seasons. The wet season begins in March and stops towards the end of October. According to major economic activity in the area is agrarian in nature and majority of the people lack job opportunities [13]. Kogi East Senatorial District is the seat of Kogi State University, Anyigba where the Teaching Hospital is also located.

\section{Type of data and methods of analysis}

This study relied on secondary data obtained from the Kogi state University Teaching Hospital (KSUTH). The data obtained from the information unit of the hospital following authorization of the hospital authority was manually sorted, collated and analysed using the Statistical Package for Social Science Analysis, (SPSS) 20.0. The demographic variables of the patients were presented in tables using descriptive statistics of frequency distribution.

Table 1: Socio-demographic Characteristics of Patients Attending Kogi State University Teaching Hospital, Anyigba.

\begin{tabular}{|c|c|c|}
\hline Variables & Frequency & Percentage \\
\hline \multicolumn{3}{|l|}{ Age range } \\
\hline 40- 49 & 6 & 10.3 \\
\hline $50-59$ & 12 & 20.7 \\
\hline $60-69$ & 17 & 29.3 \\
\hline 70 and above & 23 & 39.7 \\
\hline Total & 58 & 100 \\
\hline \multicolumn{3}{|l|}{ Education level } \\
\hline No formal education & 45 & 77.6 \\
\hline Primary education & 4 & 6.9 \\
\hline Secondary education & 5 & 8.6 \\
\hline Tertiary education & 4 & 6.9 \\
\hline Total & 58 & 100 \\
\hline \multicolumn{3}{|l|}{ Occupation } \\
\hline Civil servant & 12 & 19 \\
\hline Farming & 23 & 39 \\
\hline Trading & 16 & 27 \\
\hline Artisan & 9 & 15 \\
\hline Total & 58 & 100 \\
\hline \multicolumn{3}{|l|}{ Religion } \\
\hline Christianity & 19 & 32.8 \\
\hline Islam & 22 & 37.9 \\
\hline ATR & 17 & 29.3 \\
\hline Total & 58 & 100 \\
\hline
\end{tabular}


Table 2: PSA Levels of Patients Attending Kogi State University Teaching Hospital, Anyigba.

\begin{tabular}{|c|c|c|}
\hline Variables & Frequency & Percent \\
\hline $0-4$ & 8 & 13.8 \\
\hline 05-Sep & 6 & 10.3 \\
\hline 10 and above & 44 & 75.9 \\
\hline Total & 58 & 100 \\
\hline
\end{tabular}

Table 3: Motivation for PSA Screening among Patients Attending Kogi State University Teaching Hospital, Anyigba.

\begin{tabular}{|c|c|c|}
\hline Variables & Frequency & Percentage \\
\hline Clinical Request & 55 & 94.8 \\
\hline Routine Request & 3 & 5.2 \\
\hline Total & 58 & 100 \\
\hline
\end{tabular}

Furthermore, the hypotheses posed by the study were analysed using the linear regression analysis. The individual and sum of the sociodemographic characteristics of the respondents were analysed for better understanding.

\section{Data presentation and analysis}

The data for this study was collected from the information unit of the Kogi State University Teaching Hospital, Anyigba. It includes the Socio-demographic characteristics, motivation for PSA screening and level of PSA among patients who utilized the PSA screening services located at the University Teaching Hospital within a period of five years (2013-2018). The data were analysed in both descriptive and inferential statistics and presented in tabular form (Table 1).

\section{KSUTH health information unit, 2019}

The table above reveals that the total number of patients who utilized the PSA services is low compared to the general population of the vulnerable people and the period of the study. The sociodemographic characteristics of the respondents reveal that patients who are between the age range of 70 years and above are the majority with a percentage point of 39.7. This is followed by patients who are between the age range of percent of the respondents are between the age range of 59-60 with the percentage point of 21.3. Furthermore, patients between the age range of 50-59 attracts 20.7 percentage point followed in decreasing order by patients between the age range of 40-49 years who scored 10.3 percentage points. On education, a significant number of the respondents representing 77.6 percent have no formal education. Patients with secondary education accounted for 8.5 percent of the patients while Primary or Tertiary education accounts for 6.9 percent, respectively.

In addition, data on the occupation of patients reveals that farming is the domineering occupation with 39 followed by trading with occupies 27 percent. Civil servant had 19 percent score and Artisans occupy 15 percent score respectively.

Finally, data on the religious affiliation of patients show that 37.9 percent of them are adherents of Islamic religion, 32.8 are Christians while 29.3 are adherents of African Traditional Religion (ATR) (Table 2).

Data in Table 3 above representing the prostate antigen level of patients screened at the University Teaching Hospital reveals that 75.9 percent of the patients investigated had PSA level of 10 and above, 13.8 percent of them had a level of $0-4$ while 10.3 percent of them had a level of 5-9 (Table 3).

Data in Table 4 above representing patients' motivation for Prostate Antigen Screening revealed that a substantial percentage of the patients who utilized the PSA services were screened on clinical request while only 5.2 percent of them utilized the service on routine request.

\section{Presentation and analysis of research hypotheses}

Two hypotheses were tested to investigate the relationship between patients' demographic characteristics and the utilization of PSA screening services. The hypotheses were tested using multiple regression analysis. The table above shows the influence of sociodemographic characteristics on the utilization of PSA services among the vulnerable population of the Igala people of North Central Nigeria. The result of the multiple regression analysis reveals that motivation for utilization of PSA services among the study population is influenced by demographic characteristics. The sum of demographic factors shows that $\mathrm{p}=.000<0.05$. Similarly, the individual contribution of the demographic factors: age $=.048<0.05$, education. $000<0.05$, occupation. $001<0.05$ except religion. $622>0.05$. Although religion is not a significant factor, the sum influence of the demographic characteristics on the utilization of PSA services means that that the hypothesis is rejected (Table 4).

The table above shows the influence of socio-demographic characteristics on the PSA level of patients who utilized the PSA services at the university Teaching Hospital The result of the multiple regression analysis reveals that PSA level ( 0-4, 5-10 and greater than 10) is determined by socio-demographic characteristics of the respondents. The result of the analysis revealed that the $p$ value of the sum of the demographic factors age, education, religion and occupation is significant $(\mathrm{p}=.012<0.05)$. However, the contribution of individual demographic factors age, $(\mathrm{p}=.992)$ education, $(\mathrm{p}=.691)$ religion, $(\mathrm{p}=.002)$ and occupation, $(\mathrm{p}=.004)$ showed mixed PSA levels. On the strength of this finding, the hypothesis is rejected (Table 5).

\section{Discussion of Findings}

This study was aimed at establishing an empirical link between the socio-demographic characteristics of patients and the utilization of PSA services in terms of motivation for utilization as well as the PSA levels of patients. Consequently, the age range of patients, level of education, occupation and religion were the socio-demographic variables utilised in this study. The socio- demographic feature of age reveals that patients between the age range of 70 and above occupied the highest category of people who utilized the service. The finding showed a decreasing age range with decreasing trend of the utilization of the screening services. This is consistent with the finding of who correlated increasing age with the incidence of prostate cancer [14]. In a related dimension, data on education reveals that majority of the patients representing 77.6 percent have no formal education.

The result of the hypothesis which investigated the influence of demographic characteristics on utilization of PSA services was rejected. This shows that age, 0.04 education 0.00 and occupation 0.02 except religion with $r=.006>$ than 0.05 predicts utilization of PSA services in the study area. This finding is consistent with the finding 
Table 4: Multiple regression analysis showing the influence of demographic characteristic on utilization of PSA services.

\begin{tabular}{|c|c|c|c|c|c|c|c|c|c|c|c|c|}
\hline & Sum of Squares & Df & Means Square & $\mathbf{R 2}$ & $\mathbf{F}$ & $\mathbf{P}$ & Variables & Means & Std. Dev & B & $\mathbf{T}$ & $\mathbf{P}$ \\
\hline \multirow[t]{2}{*}{ Regression } & 10.766 & 3 & 3.58 & & 10.52 & 0 & Age & 5.62 & 2.37 & 0.068 & 2.02 & 0.048 \\
\hline & & & & & & & Education & 1.44 & 0.921 & -397 & -507 & 0 \\
\hline \multirow[t]{2}{*}{ Residual } & 18.889 & 54 & 0.35 & & & & Religion & 1.84 & 0.6435 & 0.061 & 0.054 & 0.622 \\
\hline & & & & & & & Job & 1.52 & 0.543 & -385 & -503 & 0.001 \\
\hline Total & 29.65 & 57 & & & & & & & & & & \\
\hline
\end{tabular}

Table 5: Multiple regression analysis showing the influence of demographic characteristic on the PSA level of patients who utilized.

\begin{tabular}{|c|c|c|c|c|c|c|c|c|c|c|c|c|}
\hline & Sum of Squares & Df & Means Square & $\mathbf{R 2}$ & $\mathbf{F}$ & $\mathbf{P}$ & Variables & Means & Std. dev & B & $\mathbf{T}$ & $\mathbf{P}$ \\
\hline \multirow[t]{2}{*}{ Regression } & 0.517 & 3 & 1.72 & & 4.002 & 0.012 & Age & & 2.37 & 0.015 & -123 & 0.902 \\
\hline & & & & & & & Education & 1.44 & 0.921 & -51 & -400 & 0.691 \\
\hline \multirow[t]{2}{*}{ Residual } & 2.32 & 54 & 0.043 & & & & Religion & 1.84 & 0.6435 & -415 & 3.33 & 0.002 \\
\hline & & & & & & & Job & 1.52 & 0.543 & -385 & 3.35 & 0.004 \\
\hline Total & 2.854 & 57 & & & & & & & & & & \\
\hline
\end{tabular}

of who argued that low socio-economic status are significantly related to prostatic diseases among Blacks in the United States of America [9]. This is also true of farming and trading in the study area that correlates more with poor socio economic status. Even the civil servants who participated in the study may be at the bottom cadre of the civil service. This is because, majority of the patients are either uneducated or only have basic or secondary education which can in most cases offer menial and unprofessional jobs in the civil service.

In a related development, findings about the PSA levels indicate that significant percentage of the participants representing 75 percent have PSA levels of 10 and above. This level is not only high but suggestive of serious prostatic diseases that requires further clinical enquiry. It is also suggestive of the fact that patients have failed to utilize the screening services in the past there by leading to heightened levels that are correlated with serious morbidity, disability and mortality. The result of the hypothesis which also linked demographic characteristics with PSA levels was rejected. Hence, age range, education and occupation of the respondents influence PSA levels in the study area. This is in line with who argue that relationship exists between prostatic diseases and socio-economic characteristics of the respondents [9]. This finding also supports who reveal that although, prostate cancer is a growing problem in Nigeria [7], and early screening is not a common practice.

Finally, finding on screening motivation reveal that more than 94 percent of the patients participated on clinical request. This suggests that it was not on their personal volition to utilize the service. This confirms the report of poor utilization of prostate screening services among vulnerable men in Africa. The implication of this is that a significant proportion of PSA screening utilization in the study area is dependent on clinical suspicion which underscores the essence of the services. This finding also coincides with who argue that early screening is not a common practice and the implication according to $[7,15]$. Is that many prostate cancer cases therefore present late with symptoms of local invasion or distant metastasis [16].

\section{Conclusion and Recommendations}

This paper is a descriptive and diagnostic study which uses secondary data to establish a link between demographic characteristics and the utilization of prostate cancer services at the
Kogi State University Teaching Hospital, Anyigba. The result of the test showed that in the period of five years under study, only few (58) percent and insignificant number of the vulnerable population utilized the services. In addition to this, more than 94 percent of those who utilized the services did so on clinical recommendations.

But more worrisome is the high PSA levels of greater number of those participants.

\section{On the strength of these findings, the study recommends that}

The mass media should create awareness on the rising incidence of prostate cancer as well as those vulnerable to the disease. Community education approach should be adopted by the FMOH and non- governmental organizations using occupational groups on the benefits of early screening and detection on effective management of prostate cancer. The Federal Ministry of Health should introduce a reward system mechanism into prostate cancer screening programmes to make it attractive to the vulnerable population.

\section{References}

1. Lozano R, Naghavi M, Foreman K, Lim S, Shibuya K, et al. (2012) Global and regional mortality from 235 causes of death for 20 age groups in 1990 and 2010: a systematic analysis for the Global Burden of Disease Study 2010. Lancet 380: 2095-2128.

2. Sigrid VC (2018) Prostate cancer screening with (PSA) test: a systematic review and meta-analysis. BMJ 362: k3519.

3. WHO (2009) Fighting non-communicable disease: Africa's silent killers. Afr health monitor pp: 1-60.

4. IARC (2014) Stewart BW, Wild CP (Eds). World cancer report. World health organ.

5. Oladimeji O, Bidemi YO, Olufisayo JA, Solo AO (2010) Prostate cancer awareness, knowledge and screening practices among older men in Oyo State, Nigeria. Int Q Community Health Educ 30: 271-286.

6. Marks S (2009) Prostate and cancer: A family guide to diagnosis, treatment, and survival. Da Capo Lifelong Books; $\left(4^{\text {th }}\right.$ edn) Cambridge Deacapo pp: 384.

7. Ogundele SO, Odunayo SO (2015) A survey of awareness of prostate cancer and its screening among men attending the outpatient clinics of a tertiary health centre in Lagos Nigeria. Niger J Surg 21: 115-118.

8. Rebeek TR, Devesa SS, Chang BL, Bunker CH, Cheng I, et al. (2013) Global patterns of prostate cancer incidence, aggressiveness and mortality in men of African descent. Prostate cancer 2013: 560857.

9. Moses A, Zhao Z, Fowke J (2017) The impact of sociodemographic factors 
Citation: Akwu PB, Shaibu GO and Omotoso OD. Utilization Central Nigeria. J Hum Anat Physiol 2019;3(1): 5.

and PSA screening among low-income Black and White men: data from the Southern Community Cohort Study. Prostate and Prostatic Dis 20: 424-429.

10. Globocam cancer fact sheet (2012) Cervical cancer. World health organ.

11. Salako AA, Arowolo OA (2009) Incidental carcinoma of the prostate gland presenting with initial manifestation of disseminated intravascular coagulopathy (dic) in a middle aged man: a case report. Cases J 2: 144

12. Miachi TA (2012) Kasfir on Miachi, 'The incarnate being phenomenon in African Culture: anthropological perspectives on the Igala of North-Ccentral Nigeria'. Ibadan: Kraft Books pp: 388.
13. Negedu IA (2014) The Igala traditional religious system: Between monotheism and polytheism. J Afr Stud pp: 116-129.

14. Ogunbiyi JO, Shittu OB (1999) Increased incidence of prostate cancer in Nigerians. J Natl Med Assoc 91: 159-164.

15. Oliver JS (2008) Prostate cancer screening patterns among African American Men in the Rural South. Georgia Univeristy, Nursing Dissertations pp: 1-101.

16. Magnus M (2004) Prostate cancer knowledge among multi ethnic Blacks. J Natl Med Assoc 96: 650-656 